\title{
O Luto Velado: A Experiência de Viúvas Lésbicas em uma Perspectiva Fenomenológico-Existencial
}

\author{
Ana Carolina Arima ${ }^{1}$ \\ Joanneliese de Lucas Freitas \\ Universidade Federal do Paraná, Curitiba, PR, Brasil
}

\begin{abstract}
Resumo
O presente trabalho buscou compreender as vivências de viúvas lésbicas desde uma perspectiva fenomenológico-existencial. Foram realizadas duas entrevistas fenomenológicas abertas, com a seguinte pergunta disparadora: "Como foi para você perder a sua esposa?". As entrevistas foram analisadas de acordo com o método fenomenológico de Giorgi. Os dados foram agrupados nas seguintes constituintes essenciais que descrevem a estrutura da vivência da viuvez feminina homossexual: Discriminação, Perda de sentido do mundo-da-vida, Solidão, Mudanças no humor e na saúde, Reestruturando a rotina, Alterações no projeto de vida afetiva, Falta de reconhecimento do ser-casal, Invisibilidade do sofrimento, Silenciamento, Limitação da expressão da dor, Suporte da rede de apoio, Rejeitada ou acolhida pelas famílias, Necessidade de buscar seus direitos e Necessidade de autorrespeito e autorreconhecimento como lésbica. Os resultados evidenciam indicativos de sofrimento mental na viuvez lésbica, haja vista o não reconhecimento social e a deslegitimação do afeto e da perda entre estes casais. Conclui-se que redes de apoio fortes e estruturadas e espaços de acolhimento estruturados são fundamentais para a ressignificação da experiência de luto e a minimização de seu sofrimento.
\end{abstract}

Palavras-chaves: Luto, viuvez, lesbianismo, Psicologia Fenomenológico-Existencial.

\section{The Veiled Bereavement: The Experience of Lesbians Widows in a Phenomenological-Existential Perspective}

\begin{abstract}
The present study aim understand the experiences of lesbians widows according to an existentialphenomenological perspective. Two phenomenological open-end interviews were conducted with the following starter question: "How was it for you to lose your wife?". The interviews were analyzed according to the Giorgi's phenomenological method. Data were grouped into the following essential constituents which describe the structure of the homosexual female widowhood experience: Discrimination, Loss of life-world's meaning, Solitude, Changes in mood and health, Restructuring routine, Changes in affective life's project, Lack of recognition of being a couple, Suffering invisibility, Being silenced, Limitation of pain's expression, Support network, Rejected or accepted by the families, Need to look for their rights and Need for self-respect and self-recognition as lesbian. The results indicate mental suffering in homosexual widowhood due to the lack of social recognition and lack of legitimacy of lesbian couples' affection and loss. We conclude that a structured support network and structured health care are essential to minimize suffering in lesbian widowhood and to construct new meanings in bereavement.
\end{abstract}

Keywords: Bereavement, widowhood, lesbianism, Phenomenological-Existential Psychology.

Endereço para correspondência: Praça Santos Andrade, 50, S1. 215, Ala Alfredo Buffren, Centro, Curitiba, PR, Brasil 80060-240. Fone/fax: 33102625. E-mail: anaarima@gmail.com e joanneliese@gmail.com 


\section{El Duelo Velado: La Experiencia de las Viudas Lesbianas en una Perspectiva Fenomenológica-Existencial}

\section{Resumen}

Este estudio trata de comprender las experiencias de las viudas lesbianas desde una perspectiva existencial-fenomenológica. Dos entrevistas fenomenológicas abiertas se llevaron a cabo con la siguiente pregunta desencadenante: “¿Cómo fue para usted la pérdida de su esposa?”. Se analizaran las entrevistas de acuerdo con el método fenomenológico de Giorgi. Los datos se agrupan en los siguientes componentes esenciales que describen la estructura de la experiencia de la viudez femenina homosexual: Discriminación, Pérdida del sentido del mundo de la vida, Soledad, Cambios de estado de ánimo y de la salud, Cambios en la rutina, Cambios en el proyecto de vida afectiva, Ausencia de reconocimiento de ser-pareja, Invisibilidad del sufrimiento, Silenciamiento, Limitación de la expresión del dolor, Soporte de la red de apoyo, Rechazada o aceptada por las familias, Necesidad de hacerse oír por sus derechos y Necesidad de auto-respeto y auto-reconocimiento como lesbiana. Los resultados indican sufrimiento mental en la viudez homosexual, frente a su no reconocimiento social y a la deslegitimación del afecto y de la pérdida entre estas parejas. En conclusión, una red de apoyo fuerte y espacios de cuidado estructurados son fundamentales para nuevos sentidos del duelo y para la reducción de su sufrimiento.

Palabras clave: Duelo, viudez, lesbianismo, Psicología fenomenológica-existencial.

O luto é caracterizado pela literatura como uma reação esperada e normal diante de uma perda significativa (Parkes, 1998). Com a morte de uma pessoa próxima rompe-se um vínculo que muda a rotina dos enlutados, seus valores e o sentido da vida, conduzindo frequentemente a questionamentos sobre a própria existência (Freitas, 2013). Além de ser uma experiência desorganizadora, o luto e seus processos ocorrem de formas distintas para cada pessoa e, em alguns casos, pode até mesmo nunca terminar (Broderick, Birbilis, \& Steger, 2008; Hart, 2008; Kovács, 1992). Portanto, não se trata de uma experiência generalizável, já que o vínculo do enlutado com o falecido é único, do mesmo modo que são as circunstâncias da morte e suas causas (Kovács, 1992). É reconhecido o impacto da cultura na elaboração dessa experiência (Bent \& Magilvy, 2006; Freitas, 2013; Parkes, 1998). Dentro deste contexto, nota-se que a sociedade ocidental contemporânea tem abordado a questão da morte como tabu, evitando discussões e reflexões sobre a finitude (Freitas, 2013).

Dentre as diversas perspectivas psicológicas que buscam compreender o enlutamento, a psicologia fenomenológico-existencial, perspectiva adotada no presente estudo, procura evidenciar as experiências vividas neste processo, em seus modos de articulação dentro de um dado contexto e uma dada cultura. Segundo Freitas (2013), a psicologia fenomenológico-existencial investiga a vivência e o sentido da relação rompida pela morte para o enlutado, buscando a compreensão dessas vivências enquanto fenômenos. Isto é, a fenomenologia, retornando às vivências que emergem no entrelaçamento entre ser e mundo, ao estudar o luto se detém na relação entre o enlutado e a pessoa falecida (Freitas, Michel, \& Zomkowski, 2015). Discorrer sobre o luto em uma perspectiva fenomenológico-existencial implica pensar sobre a alteridade e sobre o mundo partilhado perdido. Nesta perspectiva, calcada radicalmente na concepção de intersubjetividade, perder o outro é perder também aspectos de si mesmo, de sua pessoalidade e de seu mundo. De modo divergente em relação às outras perspectivas tradicionais, a psicologia fenomenológico-existencial entende não ser possível "superar" o luto, mas sim ressignificá-lo, alcançando "um novo se relacionar com o que se perdeu do outro e, portanto, o que se perdeu de possibilidades de sua existência singular enquanto ser-no-mundo" (Freitas, 2013, p. 104). Segundo Freitas et al. (2015), a vivência do luto é uma experiência do- 
lorosa e abrupta que, pelo seu caráter intersubjetivo, implica em uma experiência de perda de sentido. É exigida do enlutado, portanto, a tarefa existencial de ressignificar suas experiências, para que esse desenvolva autonomia e encontre forças para enfrentar as dificuldades, abrindo espaço para novas possibilidades (Ferreira, Leão, \& Andrade, 2008).

Um tipo de luto comum é a viuvez. A literatura aponta que a viuvez tende a ser especialmente estressante para as mulheres (Broderick et al., 2008). Em seus estudos, Parkes (1998) relata que viúvas frequentemente apresentam perda de apetite e peso, dificuldades para dormir, irritação, ansiedade e tensão. Além disso, elas podem ter sensações de insegurança, incapacidade de enfrentar a vida, desproteção, tendo que lidar com a solidão e a falta de alguém para compartilhar o cotidiano. Com a morte do cônjuge, há a necessidade de a/o sobrevivente aprender novos papéis e responsabilidades, alterando planos, hábitos, circunstâncias e comportamentos (Ferreira et al., 2008).

\section{A Viuvez Lésbica}

Estudos associados ao luto em casais homossexuais ainda são escassos comparados aos já publicados sobre viuvez heterossexual (Bent \& Magilvy, 2006; Broderick et al., 2008; Jenkins, Edmundson, Averett, \& Yoon, 2014; Whipple, 2006). Aqueles trabalhos que investigam casais do mesmo sexo concentram-se em homens gays que perderam seus companheiros, além de focarem frequentemente na viuvez envolvendo HIV (Bent \& Magilvy, 2006; Bristowe, Marshall, \& Harding, 2016; Broderick et al., 2008; Jenkins et al., 2014).

Entende-se que as vivências de casais heterossexuais diferem tanto das vivências de casais envolvendo dois homens quanto daquelas envolvendo casais de duas mulheres - além das diferenças existentes entre casais gays e casais de lésbicas (Bent \& Magilvy, 2006; Broderick et al., 2008; Jenkins et al., 2014). Em alguns casos, por exemplo, as famílias desconhecem a relação homossexual do parente ou mesmo a desaprovam por preconceito, diminuindo a rede de apoio do enlutado, uma das grandes facilitadoras do processo de ressignificação do luto. Contudo, o estudo de Bristowe et al. (2016), aponta para o fato de que a rede de apoio de casais homossexuais está mais fortemente relacionada aos vínculos dentro da comunidade LGBT do que aos vínculos familiares.

A despeito de a experiência de viuvez englobar elementos comuns a todos os casais, é destacado pela literatura que a atenção em saúde mental deve levar em conta as especificidades de cada grupo. Quando as especificidades não são compreendidas, corre-se o risco de serem tomadas como padrão as experiências de heterossexuais, tornando invisíveis certos sofrimentos, tal como ocorre, por exemplo, na compreensão do envelhecimento das pessoas transexuais e na viuvez lésbica (Bristowe et al., 2016; Broderick et al., 2008; Jenkins et al., 2014; Stevens \& Hall, 1998; Whipple, 2007).

Os estudos envolvendo viuvez em casais de lésbicas demonstram que os sentimentos de solidão e isolamento são mais fortes entre viúvas que não revelavam a natureza de seus relacionamentos, nos ditos relacionamentos desprivilegiados ou invisibilizados, já que seus lutos se tornam tão invisíveis quanto seus relacionamentos (Bristowe et al., 2016; Broderick et al., 2008; Jenkins et al., 2014; Whipple, 2007). Frequentemente essas enlutadas não conseguem nem mesmo perceber que precisam de apoio e tempo para viverem seus lutos, já que este é considerado como simbólico e não real (Jenkins et al., 2014; Lenhardt, 1997).

Os lutos desprivilegiados são aqueles experienciados em relacionamentos não legitimados socialmente. É um luto complicado, que envolve a exclusão dos serviços de cuidado especializados, a falta de apoio social, a exclusão dos rituais fúnebres e provocam dificuldades práticas e legais (Jenkins et al., 2014; Lenhardt, 1997). Entretanto, revelar a natureza do relacionamento apresenta ganhos e perdas, além de ser arriscado. Os estudos de Broderick et al. (2008) e de Whitman, Cormier e Boyd (2000), expõem as consequências de se assumir como lésbica publicamente: sofrimento por perdas inter e intrapessoais, tais como o afastamento da família, da religião e de 
grupos étnicos. Os mesmos autores ainda alertam que expor sua sexualidade pode até mesmo ameaçar a vida e a segurança econômica dessa mulher, sua segurança pessoal, de sua família e a custódia dos filhos. A ameaça de tais perdas está vinculada a preocupações quanto à exposição de sua vida pessoal em lugares públicos como trabalho, escola e família. As lésbicas se veem com a tarefa de avaliar constantemente sua segurança emocional e física, levando a diferentes tipos de estresse ao longo de seu ciclo de vida (Whitman et al., 2000).

O acolhimento que a viúva lésbica receberá está fortemente relacionado com o quão assumido era o relacionamento do casal (Bristowe et al., 2016; Broderick et al., 2008; Jenkins et al., 2014). A rede de amigos e pessoas próximas que apoiavam o casal é importante, especialmente nos casos em que as famílias de origem não aceitavam o relacionamento. A literatura reporta que em muitos casos, além da oposição da família ao relacionamento, não há o registro de casamento ou de união estável. Nestes casos, após a morte da esposa, a família tende a negar ou limitar o acesso da enlutada aos ritos fúnebres, não as reconhecendo como casal (Bent \& Magilvy, 2006; Broderick et al., 2008; Jenkins et al., 2014). Há também relatos de mulheres impedidas de acompanhar suas esposas em seus últimos momentos, por não serem legalmente casadas. Outros desafios comuns relatados por viúvas lésbicas envolvem batalhas judiciais quanto a herança com a família da falecida e a problemas financeiros devido à falta de reconhecimento da relação (Bent \& Magilvy, 2006; Jenkins et al., 2014).

No Brasil a união estável para casais do mesmo sexo é reconhecida pelo Supremo Tribunal Federal (STF) desde maio de 2011, quando os ministros deste tribunal, ao julgarem a Ação Direta de Inconstitucionalidade (ADI) 4277 e a Arguição de Descumprimento de Preceito Fundamental (ADPF) 132, reconheceram a união estável para casais do mesmo sexo. Foi entendido pelo STF que em seu artigo $3^{\circ}$, inciso IV, a Constituição Federal proíbe qualquer discriminação em virtude de sexo, raça, cor e que, nesse sentido, ninguém pode ser diminuído ou discriminado em função de sua preferência sexual
(STF, 2011). Em 2013, o Conselho Nacional de Justiça (CNJ) proibiu as autoridades competentes de se recusarem a celebrar o casamento civil ou, até mesmo, de converter união estável em casamento entre pessoas de mesmo sexo (STF, 2013). Segundo o Instituto Brasileiro de Geografia e Estatística (IBGE, 2014) apenas entre 2013 e 2014 houve um aumento de $31,2 \%$, dos casamentos entre pessoas do mesmo sexo o que, em números absolutos, representou 1153 uniões homoafetivas $^{2}$ a mais, sendo que $50,3 \%$ destes eram entre cônjuges femininos e 49,7\%, entre cônjuges masculinos. Entretanto, consideramos que as relações se definem de várias maneiras e não necessitam de registro civil para serem reconhecidas, porém no caso dos casais homossexuais essa questão tem tomado relevância nos últimos anos pelo debate que provocou na sociedade, bem como os impactos consequentes nas experiências de viuvez, no que tange ao reconhecimento público e de direitos de um casal. A sociedade brasileira tende a reconhecer as relações homossexuais quando determinadas pelo afeto, o que é reforçado no campo jurídico, mas que não ocorre entre casais heterossexuais, que são reconhecidos pelos seus direitos elementares de liberdade, igualdade e não-discriminação, não precisando do amor romântico para serem definidos e reconhecidos como família (Costa \& Nardi, 2015).

A literatura aponta que muitas lésbicas prezam por um equilíbrio de poder na relação, isto é, igualdade na divisão das tarefas e nas responsabilidades financeiras, intimidade emocional e autonomia pessoal no casal (Whitman et al., 2000). Os estudos com casais lésbicos defendem que essa valorização da intimidade do casal, aliada às perdas sociais anteriormente citadas, podem fazer com que a viúva perca, juntamente com a esposa, parte considerada mais integradora e fundamental de sua identidade e do seu mundo emocional e social (Broderick et al., 2008; Jenkins et al., 2014; Whipple, 2006, 2007).

Por ser tratar de uma citação, o termo "união homoafetiva" utilizado pelo IBGE foi mantido no trecho. 
Psicólogos e assistentes sociais sentindo a falta de literatura relativa ao tema passaram a escrever sobre o assunto, abordando recomendações no manejo clínico para tratar essas enlutadas (Bent \& Magilvy, 2006; Broderick et al., 2008; Jenkins et al., 2014). O curioso foi que não foi encontrado nenhum trabalho sobre o tema em língua portuguesa nas bases de dados pesquisadas, a saber: Portal CAPES e SciELO (Scientific Electronic Library Online), apontando para uma urgência de investigações sobre o tema no âmbito nacional. Em uma revisão sistemática de literatura sobre a viuvez entre gays, lésbicas e transexuais, Bristowe et al. (2016) apontam que o tema é escasso mesmo na literatura de língua inglesa. Os estudos revelam a necessidade de se desenvolver conhecimento sobre como atender tal população, já que a rede de suporte tem excluído e negligenciado as viúvas lésbicas que precisam de apoio (Bent \& Magilvy, 2006; Bristowe et al., 2016; Jenkins et al., 2014).

Quanto ao manejo clínico do psicólogo, Broderick et al. (2008) afirmaram que muitas lésbicas podem não procurar o consultório, porém, mesmo assim, cabe aos profissionais de saúde mental estarem cientes da potencial influência de determinadas condições sociais no enfrentamento, adaptação e construção de significado da morte para estas viúvas. Os autores alertam que a morte da companheira pode ressoar perdas anteriores, como as perdas sociais relacionadas à homofobia (amigos, famílias, comunidade religiosa), de modo que a viúva pode sentir-se mais fortemente isolada, abandonada e rejeitada. $\mathrm{O}$ profissional que atender essa enlutada deve avaliar cuidadosamente a rede de apoio disponível, ajudar a desenvolver novos sentidos existenciais, encorajando-a a viver rituais e tradições que expressem sua preferência individual, seja ela relacionada à etnia ou à cultura LGBT, afirmando a transição para novos papéis e novas identidades e perspectiva de mundo. Bristowe et al. (2016) propõem um modelo para o cuidado de viúvos gays e viúvas lésbicas, bem como para viúvos e viúvas transexuais, que esteja apoiado na avaliação do quanto sua identidade é conhecida e aceita por sua rede social, porém não apresenta uma reflexão sobre a especificidade da viuvez lésbica, apesar de destacar que as especificidades e diferenças entre gays, lésbicas, transexuais e bissexuais devam ser melhor estudadas.

Compreender e conhecer as especificidades da viuvez lésbica pode contribuir para diminuir a invisibilidade de suas relações e desafios decorrentes, bem como para que psicólogos e outros profissionais de saúde possam pensar em intervenções e programas mais apropriados para as viúvas, atualmente inexistentes no Brasil. $\mathrm{O}$ único estudo internacional sobre o tema na perspectiva fenomenológica é consoante com outros estudos, ao apontar como elemento chave e significativo para a compreensão dessa vivência o fato de a relação ser de conhecimento público ou não (Bent \& Magilvy, 2006). Segundo os autores, o reconhecimento social do vínculo impacta em três aspectos importantes da vivência da viuvez lésbica, a saber, as possibilidades para reflexão e ressignificação da própria experiência, o acesso ou não ao suporte grupal e a intensificação de problemas e situações vividas no contexto de uma relação não reconhecida, como por exemplo, problemas legais ou de participação em rituais.

Buscar compreender as experiências de enlutamento vividas por viúvas lésbicas pode abrir um campo de estudos sobre as dificuldades enfrentadas por estas mulheres e as especificidades de seu sofrimento, além de lançar luz em um problema que ainda tem lugar restrito nas políticas públicas brasileiras, a saber, a atenção à população LGBT. Por conseguinte, busca-se neste trabalho, por meio de um estudo fenomenológico, compreender e discutir as especificidades das experiências e sentidos vividos na viuvez lésbica e contribuir para expandir o conhecimento e a visibilidade do sofrimento de seu enlutamento.

\section{Método}

Esta é uma pesquisa fenomenológica, de caráter exploratório e qualitativo. Optou-se, portanto, pelo método fenomenológico de Giorgi (Giorgi \& Sousa, 2010).

Com o objetivo de encontrar participantes, a pesquisa foi divulgada nas redes sociais nos seguintes grupos: mães pela igualdade, associação 
brasileira de estudos da homocultura, cafezinho (grupo de relacionamento para mulheres interessadas em outras mulheres em Curitiba), colmeia, ONG dignidade, Pastoral Anglicana da Diversidade de Curitiba e Liga Brasileira de Lésbicas, além de contatos pessoais e divulgação da pesquisa entre amigos e conhecidos. Os critérios de inclusão das participantes foram: (a) estar no relacionamento quando a parceira faleceu; (b) que esse relacionamento tivesse durado no mínimo um ano.

Mesmo divulgando nas redes sociais e para pessoas próximas, ou que se acreditava estarem ligadas às pessoas LGBT como os grupos supracitados, poucos diziam conhecer lésbicas que ficaram viúvas. Devido a dificuldade de encontrar participantes, foram realizadas apenas duas entrevistas. Tal dificuldade no recrutamento também é apontada por Bristowe et al. (2016), que asseveram a relevância de serem pensados métodos de recrutamento mais eficazes quando se trata de pesquisas com minorias.

\section{Participantes}

Hipólita é uma mulher negra de 62 anos, viúva há 15 anos. Ao realizar uma cirurgia de estômago, sua esposa descobriu um câncer que se estendeu pelo fígado e pâncreas, levando-a posteriormente à morte. $\mathrm{O}$ casal viveu junto durante quatro anos. Moravam em um apartamento com dois filhos, fruto do primeiro casamento de Hipólita. Embora as famílias das duas mulheres soubessem da relação, Hipólita relatou que na época não se assumia publicamente como lésbica. Atualmente, está casada com outra mulher.

Ártemis é uma mulher de 57 anos, psicóloga e viúva há dois. Sua esposa faleceu em decorrência de um câncer, passando por tratamentos de quimioterapia e uma cirurgia. $\mathrm{O}$ casal não era casado legalmente e se relacionou por 26 anos. Embora a família da falecida soubesse que elas moravam juntas, não reconhecia o relacionamento amoroso.

\section{Instrumentos e Procedimentos de Coleta de Dados}

As entrevistas incluíram dados demográficos como nome, idade, o tempo de duração do relacionamento, há quanto tempo acontecera o falecimento da esposa. Uma vez que a pesquisa fenomenológica tem o foco na experiência vivida, utilizou-se a seguinte pergunta disparadora como recurso metodológico: "Como foi para você perder a sua esposa?". No primeiro momento da entrevista, foi apresentada por e-mail às participantes a proposta de pesquisa e obtido o consentimento para participação e divulgação dos dados, mediante a assinatura do TCLE. As duas entrevistas se iniciaram com as perguntas sobre os dados demográficos, seguida da pergunta disparadora. A entrevista de Hipólita ocorreu em uma sala no local de trabalho da entrevistada e durou 23 minutos. A entrevista com Ártemis foi realizada via Skype e teve a duração de 53 minutos. Ambas foram gravadas com consentimento das participantes, transcritas e posteriormente analisadas.

\section{Procedimentos de Análise de Dados}

O método de análise utilizado foi o método fenomenológico de Giorgi (Giorgi \& Souza, 2010). O método de Giorgi, composto por quatro passos, foi aplicado às duas entrevistas, a saber:

1. Estabelecimento do sentido geral;

2. Divisão das unidades de significado psicológico;

3. Transformação das unidades de significado em expressões de caráter psicológico;

4. Determinação da estrutura geral de significados psicológicos, por meio da determinação e agrupamento das chamadas "constituintes vivenciais", que seriam as vivências específicas que constituem a estrutura da vivência, no caso, da viuvez lésbica.

\section{Procedimentos Éticos}

A presente pesquisa foi aprovada em Comitê de Ética e encontra-se registrada sob número CAAE 45088815.1.0000.0102. Foram seguidas as Diretrizes e Normas Regulamentares de Pesquisa Envolvendo Seres Humanos estabelecidos pela resolução 251/97 do Conselho Nacional de Saúde. Ambas as participantes assinaram o Termo de Consentimento Livre e Esclarecido (TCLE). Os nomes utilizados são fictícios. 


\section{Resultados e Discussão}

A partir da análise das entrevistas foram encontradas 14 constituintes que descrevem a estrutura da vivência da viuvez lésbica. As constituintes vivenciais foram separadas em dois eixos tendo como centro a relação afetiva, de onde se desdobram as experiências de luto. Tais eixos, dizem respeito a duas facetas do que notamos se experienciar no luto lésbico, nomeados como " $\mathrm{O}$ Mundo da Relação" e "A Relação no Mundo". O primeiro eixo, portanto, versa sobre "O Mundo da Relação" e explora os aspectos do rompimento de um mundo existencialmente partilhado enquanto casal e inclui as seguintes constituintes: Perda de sentido do mundo-da-vida, Solidão, Mudanças no humor e na saúde, Reestruturando a rotina e Alterações no projeto de vida afetiva. O segundo eixo explicita as experiências de ser um casal de lésbicas no mundo, isto é, "A Relação no Mundo" e descreve as seguintes constituintes essenciais: Falta de reconhecimento do ser-casal, Invisibilidade do sofrimento, Silenciamento, Limitação da expressão da dor, Suporte da rede de apoio, Rejeitada ou acolhida pelas famílias, Necessidade de buscar seus direitos e Necessidade de autorrespeito e autorreconhecimento como lésbica. Foi encontrado também que as experiências que envolvem o luto vivido pelas participantes foram intensamente significadas e permeadas pela experiência de Discriminação que se apresentou, ora como figura, ora como fundo das vivências do enlutamento e se compôs, portanto, como elemento constituinte e significante de relevo em suas experiências. Destarte, por permear as experiências descritas em ambos os eixos, a vivência de discriminação será descrita antes dos eixos temáticos.

\section{Vivendo a Discriminação}

As participantes relataram a discriminação que sofreram por serem viúvas de mulheres e não de homens, corroborando que a vivência da viuvez de uma relação homossexual não pode ser comparada à heterossexual, assim como asseveram as pesquisas da área (Bent \& Magilvy, 2006; Broderick et al., 2008; Jenkins et al., 2014). Hipólita relatou que para algumas pessoas não revelava ser viúva de uma mulher, com o intuito de comparar as reações frente às diferentes formas de viuvez. Ártemis e Hipólita afirmaram que perguntas frequentes aos enlutados, como por exemplo, as causas da morte, se as viúvas e os filhos estariam bem, entre outras, não eram dirigidas a elas, como geralmente são dirigidas a viúvas e viúvos:

... eu não vejo o olhar das pessoas no sentimento de achar que aquela relação seja tão fortalecida, tão séria para nós como [acham de] um casamento "hetero". Uma viúva lésbica não é realmente uma viúva heterossexual, sabe? . . Então, aquelas perguntas todas que teriam sido feitas "Mas que pena, morreu de quê?", "E as crianças como estão?", que seria uma conversa normal, né? De uma viúva... Não, isso não existe no mundo lésbico, isso não existe. (Hipólita)

As entrevistas mostram que a discriminação da enlutada lésbica é vivida não apenas no trabalho e na sociedade em geral, mas também está densamente presente nas próprias relações familiares. Na literatura é frequente o relato de viúvas que foram impedidas de partilhar os últimos momentos, ou mesmo tiveram sua participação limitada nos rituais fúnebres, ambas vivências experienciadas por Ártemis (Broderick et al., 2008; Jenkins et al., 2014). A participante afirmou não ter tido privacidade como casal no período de adoecimento de sua esposa, pois a família da falecida a impedia ou dificultava esses momentos. Segundo ela, para conseguir ter acesso ao leito e acompanhá-la no hospital, precisou se passar por sua psicóloga.

Essa discriminação já fora notada por Bent e Magilvy (2006) que apontam que, enquanto a rede de suporte para as viúvas heterossexuais é forte, ela ainda exclui e negligencia viúvas lésbicas que também precisam de apoio. Além disso, a natureza do relacionamento também pode levar ao afastamento entre a lésbica e a família, os colegas de trabalho e a comunidade religiosa, que seriam fontes de apoio que uma viúva poderia contar, fortalecendo assim os laços dentro da comunidade LGBT (Broderick et al., 2008). 


\section{Eixo 1: O Mundo da Relação}

\section{Perda de Sentido do Mundo-da-Vida}

$\mathrm{O}$ aspecto existencial fundamental de todo luto é a perda do sentido do mundo-da-vida (Freitas et al., 2015). Ártemis relatou que com a morte da esposa, alguns planos importantes para ela, tais como projetos de viagem, trabalho e, principalmente, o de envelhecer juntas, ruíram, fazendo com que ela sentisse solidão e falta de sentido:

. . a falta de sentido é que nós tínhamos um projeto, né? Como acredito que grande maioria dos casais, né? O barato do envelhecer juntos. O que a gente vai fazer, desde os sonhos e fantasia de viagens que a gente planejava e não conseguiu realizar!

A morte é uma experiência desorganizadora que traz para as sobreviventes questionamentos e reavaliações de vários aspectos da vida e da própria atitude (Broderick et al., 2008; Freitas et al., 2015; Hart, 2008; Kovács, 1992). Com a morte de um ente querido, não se perde apenas quem morreu, mas um modo de ser próprio experienciado na relação, afetando o campo existencial da sobrevivente (Freitas, 2013). Nas palavras de Ártemis: "O lugar dela ainda está muito forte em mim. E eu me exercito assim, ficar com o que eu tive de bom dela, né? Ela me ensinou muito a alegria da vida". As limitações agora impostas pela morte impedem que alguns projetos sejam concretizados, fazendo com que a enlutada experiencie falta de perspectivas, mesmo que posteriormente, convicções e valores tenham a possibilidade de sofrerem ressignificações, assim como os sentidos existenciais.

\section{Solidão}

As entrevistadas relatam sentimento de solidão e isolamento. A experiência de isolamento e a falta de espaços para compartilhar suas vivências são encontradas nos estudos sobre viuvez lésbica e relatadas pelas duas participantes do presente estudo (Bristowe et al., 2016; Broderick et al., 2008; Jenkins et al., 2014). Mesmo que a solidão se refira ao refazer a vida sem a esposa e à falta de alguém para compartilhar a vida, nota-se que, tal como descrito pela literatura, o isolamento social vivido pelas viúvas lésbicas - decorrente da discriminação - intensifica o sentimento de solidão da viuvez (Jenkins et al., 2014), como percebe-se na entrevista de Hipólita:

Talvez a falta do dividir a dor seja um pouco maior, sabe? . . você não pode ligar pra qualquer pessoa e dizer " $A i$, tô péssima hoje". Você tem que pensar "vou ligar para quem? Para dizer que estou péssima?". Isso existe realmente!

\section{Mudanças no Humor e na Saúde}

Confirmando estudos anteriores sobre viuvez, as participantes relataram que, após a morte da esposa, sofreram alterações no humor e na saúde (Broderick et al., 2008; Hart, 2008; Parkes, 1998; Whipple, 2006). Turatti (2012) aponta que especialmente em relações com vínculo afetivo intenso é comum o adoecimento e o comprometimento somático na viuvez. Ambas as participantes relatam terem emagrecido e ficado com o humor deprimido. Ártemis afirmou que desde que ficou viúva, comer deixou de ser prazeroso. Hipólita disse que: "Eu fiquei muito angustiada e muito ansiosa, eu dormia muito pouco. Eu vivia em um estado de extremo cansaço, eu dormia pouco e tinha depressão, tinha tudo".

Destaca-se que em uma situação de invisibilidade do sofrimento, a atenção à saúde pode ficar comprometida gravemente e que amiúde se torna necessário recorrer a recursos alternativos para conseguir o cuidado adequado. Hipólita, por exemplo, expôs que quando perdeu sua esposa, conseguiu um atestado de saúde para afastar-se do trabalho e recuperar-se emocionalmente com uma médica que reconhecia seu relacionamento e, portanto, seu sofrimento. A licença por luto era um recurso inexistente aos casais homossexuais à época da perda de sua esposa.

\section{Reestruturando a Rotina}

As entrevistadas relataram que, embora tenham tido apoio de algumas pessoas próximas que reconheciam a natureza do relacionamento, a reestruturação da rotina após a morte da esposa coube somente a elas. Essa reestruturação é caracterizada por elas como um processo difícil e marcado pela solidão. As mudanças que exigi- 
ram reestruturação incluíram: recomposição da vida financeira, mudanças de casa e na própria casa, reorganização dos objetos e pertences do casal, o modo de ocupar o dia e o lazer nas horas livres. Todos estes desafios podem se tornar problemas de difícil manejo quando envolvem questões judiciais, comuns entre pessoas que perderam cônjuge do mesmo sexo (Bristowe et al., 2016; Broderick et al., 2008; Jenkins et al., 2014). No relato de Ártemis, nota-se essa questão: Outra coisa muito pesada né? Que também acho que rodeia as relações onde tem como pano de fundo a homofobia, é que tinha dois dias que ela havia morrido, a filha dela vai com o marido na minha casa, dizendo que eles estavam pensando em vender o apartamento e que já queriam levar alguém para fazer a avaliação antes de irem embora. Eles tavam só esperando a missa de sétimo dia para irem embora. Ai eu dei uma descompensada falando que ninguém ia para lá, que o apartamento era meu e tudo mais. . . a ai eu realmente não conseguia pensar em mais nada, né? Nos primeiros meses, mais de dois meses, estava totalmente fora de mim e, por pressão deles, eu assinei uma minuta abrindo mão de tudo, né? De direito de morar, de reforma, de tudo que eu fiz, que eu só reconheceria a união estável, porque a gente não tinha em papel a união estável, depois que terminasse o inventário que eles argumentavam que isso era para não ter atraso.

Estudos sobre viuvez apontam o difícil movimento de transformar o "nós" em "eu" (Parkes, 1998; Turatti, 2012; Whipple, 2006). Existencialmente, esse "nós" se trata da forma como alguém significativo se apresenta na vivência de mundo do enlutado, considerando que ambos dividiam uma temporalidade e espacialidade, um comum habitar (Freitas et al., 2015). Esse reestruturar a rotina evidenciará não apenas a ausência da cônjuge ${ }^{3}$, mas também os meandros

3 A palavra cônjuge se trata de um substantivo sobrecomum: "o" cônjuge, ou seja, apresenta um só gênero tanto para o masculino quanto para o feminino. Embora se saiba dessa regra gramatical, da opressão e da discriminação vivida pelo casal de lésbicas. Não há mais um "nós" que projeta a vida, apenas um "eu" que reorganizará a vida comum, porém, frequentemente em uma situação onde dificuldades impostas por batalhas judiciais e pouco reconhecimento da cumplicidade do casal intensificam as dificuldades de reestruturação.

\section{Alterações no Projeto de Vida Afetiva}

As entrevistadas se diferenciam no tempo de viuvez, enquanto Hipólita havia perdido a esposa há quinze anos, Ártemis era viúva apenas há dois, o que certamente influenciou no modo de perceberem seus projetos de vida afetiva. A primeira relatou estar casada novamente e lidar bem com as memórias que tem da falecida. A segunda participante contou estar desencantada com o projeto de vida afetiva, porém, demonstrou ter vontade de refazer a sua vida, aceitando a morte da esposa e deixando-a no registro de sua história, podendo assim, no futuro construir um novo projeto de vida afetiva com uma nova companheira.

Como relatado por Ártemis, a lembrança da sua esposa ainda é muito presente e viva para ela e por isso ainda não há como se relacionar com uma nova pessoa. Whipple (2006) afirma ser comum muitas viúvas lésbicas temerem o que esse "seguir adiante" significa e o que um novo relacionamento poderia trazer para suas vidas. De qualquer modo, essa constituinte aponta para o enlutamento como um processo que inclui ressignificação e novas possibilidades existenciais.

\section{Eixo 2: A Relação no Mundo}

\section{Falta de Reconhecimento do Ser-Casal}

A falta de reconhecimento social do ser-casal quando se trata de uma relação entre duas mulheres chamou atenção das entrevistadas e se apresenta como pano de fundo das suas relações

no presente trabalho optou-se por usar a palavra no feminino: "a" cônjuge. Essa escolha se fez necessária, pois o trabalho busca defender um espaço político da viuvez feminina homossexual, visto que no cenário atual, há a invisibilidade dessa condição. 
sociais, sendo um dos aspectos fundamentais da manutenção da discriminação sofrida pelas lésbicas, com impactos importantes na vivência do luto, como amplamente descrito pela literatura (Bristowe et al., 2016; Broderick et al., 2008; Jenkins et al., 2014; Whipple, 2007). Ártemis relatou que lhe foi retirado seu direito de se assumir socialmente como esposa da falecida, de registrar sua união estável e de se manter a par do que acontecia com a companheira enquanto ela estava doente: "mas muita loucura foi todo o processo da doença né? Que foi a negação da família à nossa relação". Saber da relação não é necessariamente reconhece-la como legítima. O não reconhecimento como casal - mesmo a família tendo reconhecido o amor inerente à relação - também levou a grandes interferências da família no relacionamento, à falta de privacidade na vida do casal e também à deslegitimação da viuvez:

E quando eu entrei, que ia começar a missa . . os viúvos ficam na primeira fila, todo mundo junto, essa coisa de família, não tinha lugar pra mim. Ai ficou aquele mal-estar, aonde eu vou ficar, né? Tava toda a familia de um lado da igreja no banco, e eu sentei sozinha do outro lado. . . Então, é velado, o ritual não é igual para você... eu tava tão chocada, que era capaz de ficar sentada na igreja até hoje! Eu não fazia nada, fiquei muito paralisada. Essa discriminação é muito forte!

Ártemis destacou que sua dor se relacionava a ter vivido uma união feliz, apontando para o fato de que ser um casal não se relaciona com gênero, mas com afeto: "Eu não vejo a diferença entre você ficar viúva de um casamento homo e de um casamento hetero, né? Eu diria assim: a minha dor tá em ter um casamento feliz, não importa se é homo ou hetero". Não ser reconhecido como casal é uma situação que pode ser especialmente desestruturante na viuvez, pelo impacto na (im) possibilidade de expressão da dor do luto e no reconhecimento do seu afeto e sofrimento.

\section{Invisibilidade do Sofrimento}

As entrevistadas relataram a invisibilidade do seu sofrimento, da sua sexualidade e da sua afetividade, sendo o sofrimento da viuvez, portanto, uma experiência intensificada pela discriminação. Hipólita lembrou que era incentivada a se engajar em novos relacionamentos, tendo sua dor da perda ignorada. Ártemis apreendeu seu luto como um luto velado, pouco percebido socialmente: "Mais do que o luto, é o luto e na condição de realmente me tornar invisivel, né?". Um exemplo dessa vivência foi a experiência na missa de sétimo dia de sua esposa falecida, quando não pôde ocupar seu lugar como viúva, sentando longe da família. Outro aspecto referenciado pelas entrevistadas diz respeito à facilidade com que lhes era sugerido investir em outra relação, como se a relação anterior não tivesse existido, ou não fosse tão importante, ignorando-se seu sofrimento diante do luto.

A invisibilidade do sofrimento vivida por elas é um reflexo da negação e do não reconhecimento da própria relação homossexual que havia antes da morte. Ou seja, a sociedade, segundo elas, desconsiderando a seriedade da relação, nega a vida desses casais e posteriormente, abordam sua viuvez como um processo fácil ou de rápida "superação", tal como descrito por Hipólita:

O olhar geral é "Você está tão bonita!", "Daqui a pouco você arranja outra pessoa". É outra pessoa, não tem nome né? [tom irônico] É uma pessoa né? "Você arranja outra pessoa" . . Como se fosse muito fácil, entendeu? Sair de uma relação que a pessoa havia falecido e partir pra outra, que seria uma resposta que com certeza eu não receberia se eu tivesse ficado viúva de marido, sabe? Teria tomado uma aparência muito mais emocional, sabe? "Ele era um bom marido", "morreu tão novo". Teriam vários aspectos, várias... Teriam várias... Várias palavras de conforto.

Ainda sobre a palavra superação é importante lembrar que, como defende Freitas (2013), o luto não se trata de um período a ser superado, mas sim, um período de ressignificação da relação entre a falecida e a enlutada. Nas palavras de Freitas et al. (2015), "O luto não termina, modifica-se em seu modo de apresentação. É uma vivência de incorporação desta experiência na 
vida do enlutado" (p. 23), acrescentaríamos, articulado no mundo cultural. A incorporação dessa experiência, e consequente aquisição de novos papéis e responsabilidades, como apontado em Ferreira et al. (2008), se torna mais difícil, pois fica a questão: como alterar planos, hábitos, circunstâncias e comportamentos em um mundo onde se era invisível como casal? Dito de outro modo: vislumbrar novas possibilidades existenciais, novos modos-de-ser, que antes da morte da pessoa amada não existiam, se tornam no luto desprivilegiado, profundamente desafiadores.

\section{Silenciamento}

As entrevistadas relataram que a viuvez lésbica não está incorporada na sociedade e nem mesmo no movimento LGBT, fazendo com que sua dor e suas vivências como viúvas fossem silenciadas, tal como já apontado em outros estudos (Bent \& Magilvy, 2006; Jenkins et al., 2014): "E ai como é que a gente vai construir essa viuvez? Isso não está construído, né? Isso não está construído! Dentro do movimento de lésbicas isso não está construído!" (Hipólita).

Ártemis e Hipólita relataram que as pessoas com quem conviviam - salvo as mais íntimas - evitavam comentar sobre a falecida. Segundo Hipólita, tanto a homossexualidade quanto o luto são temas relacionados ao silêncio, um silêncio que, em suas próprias palavras, "não protege ninguém". Isto é, ela afirma que tanto gays e lésbicas, quanto as enlutadas e os enlutados, são silenciados pela sociedade que não discute abertamente tais temas, tratando-os como tabu. O silêncio, diversamente do que se acredita no senso comum, não impede o sofrimento e, nesse caso, um sofrimento vivido duplamente: tanto pelas implicações da discriminação por sua orientação sexual, quanto pela perda de um ente querido, caracterizando-se também como um luto desprivilegiado. Desta forma, observa-se que as entrevistadas viveram um duplo tabu, silenciadas enquanto lésbicas e viúvas.

\section{Limitação da Expressão de Dor}

A limitação da expressão de dor vincula-se à viuvez lésbica por este ser um luto desprivilegiado, com seu sofrimento invisibilizado, o si- lenciamento sobre sua condição e sua decorrente falta de apoio social, como se percebe na fala de Hipólita:

Quem sabia, sabia que eu estava mal por aquela razão. Quem não sabia, tentava saber e eu falava "não, eu perdi uma pessoa muito querida". Eu mentia. Mas no momento em que eu dizia [que era uma mulher]: "Ah que pena", encerrava aquele assunto.

As entrevistadas relataram experimentar a ausência de espaços e pessoas com quem pudessem compartilhar seus sentimentos de luto. Hipólita contou evitar chorar e expressar seu sofrimento em ambientes públicos, como no condomínio em que morava ou no seu trabalho. Viver um luto velado fez com que as viúvas entrevistadas esperassem voltar para casa para poder chorar, procurando acolhimento entre as pessoas que sabiam e aceitavam o relacionamento. Como Hipólita relatou: "Para mim, o mais sentido é você não poder chegar no ambiente de trabalho e trazer publicamente sua viuvez... . Talvez a falta do dividir a dor seja um pouco maior, sabe?".

A limitação das possibilidades de expressão da dor do luto não é saudável para a viúva. Como apontado pela literatura (Ferreira et al., 2008; Hart, 2008; Parkes, 1998), é fundamental que a enlutada expresse seus sentimentos para lidar com as mudanças acarretadas pela morte da cônjuge, de modo que a sobrevivente consiga aceitar o falecimento, lidando melhor com essa dor e a nova vida que a desafia.

\section{Suporte da Rede de Apoio}

A rede de apoio como um facilitador do luto é amplamente discutida pela literatura (Broderick et al., 2008; Ferreira et al., 2008; Parkes, 1998; Whipple, 2007). Na experiência das entrevistadas as relações com pessoas que reconheciam suas dores foram fundamentais para confortá-las, assinalando uma vez mais a relevância do reconhecimento social do casal. Ártemis, por exemplo, descreveu como um grupo de amigas foi basilar para seu enfrentamento da viuvez quando, ao demonstrar carinho e afeto, a fortaleceram em seu momento de dor e sofrimento. Nas palavras dela: 
No período em que eu não conseguia comer... Então, organicamente eu já estava começando a ficar comprometida. Se eu comia, eu vomitava e se vomitava dava irritação no estômago e não dava para ficar sem comer. Então, elas [as amigas de Ártemis] simplesmente falaram assim "todo dia durante uma semana na sua portaria vai aparecer uma sopa". E foi muito lindo né?! [tom alegre]. Porque as pessoas viram que eu estava mal, os próprios porteiros, que já são do prédio todos esses anos, me avisavam "ó, chegou a sua sopa!". Então, o primeiro dia foi uma coisa maluca, porque eu tomava sopa chorando, "mas eu vou conseguir comer!", né? Aquela sopa que era para um dia eu tomava em dois, três. E isso me fortaleceu muito, né? O afeto de cuidarem de mim. Então eu me deixei receber esse carinho.

A rede social que apoiava o casal em seu vínculo afetivo continua sendo relevante no luto, especialmente nos casos em que as famílias de origem não aceitam o relacionamento, sendo um dos poucos apoios que as enlutadas lésbicas podem receber (Broderick et al., 2008). No caso de Ártemis, foi relevante inclusive para a manutenção de sua saúde.

\section{Rejeitada ou Acolhida pelas Famílias}

Os relatos das entrevistadas mostraram como a aceitação ou a negação da relação homossexual por parte dos familiares da cônjuge influencia na relação entre a viúva e a família da esposa após a morte dessa. Em nosso estudo, temos relatos de acolhimento, no caso de Hipólita, e não aceitação, no caso de Ártemis. Deste modo, Hipólita relatou a importância de ter recebido acolhimento e amparo da família da falecida:

. . mas eu acho que essa coisa da família dela nunca ter me abandonado teve muito a ver pela aceitação dela enquanto lésbica né? Como eles aceitavam, e aceitavam de fato, eles aceitavam mesmo, entendeu? A gente era recebida na família como uma pessoa qualquer da família, não havia essa coisa de dizer "não, não". Eram três filhas, todas casadas, todas casadas, entendeu? E isso era muito tranquilo, então isso teve!

Entretanto, na família da companheira de Ártemis, onde ela relatou sempre ter havido uma homofobia velada, pois aparentemente havia aceitação, a relação entre ela e a família da falecida se desfez. Depois do falecimento houve ruptura dos laços afetivos e desconsideração da enlutada como viúva dotada de direitos, fazendo com que ela se sentisse desrespeitada e vítima de abuso emocional:

Especificamente, na minha terapia do luto, foi recomeçar a reconstituir que nós, eu e a minha companheira, botamos muito pano quente na relação que a gente tinha, assim, verdadeiramente ver que a gente não era tão querida pela filha dela como casal, que na verdade, eu era necessária. No momento que não tem a mãe, isso eu vejo hoje, eu não sou mais necessária, sou descartável e empaco a vida deles uma vez que eu moro em um apartamento que é de herança dela, né? Questões envolvendo demasiada influência da família na herança da falecida quando não há registro legal de casamento e nem de união estável já foram documentadas por Whipple (2006). Outros estudos também já indicaram situações semelhantes em que a família de origem ou biológica da falecida desrespeitou vontades e planejamentos financeiros do casal quando estavam juntos, culminando em batalhas judiciais contra as viúvas, causando a elas maior sofrimento (Bent \& Magilvy, 2006; Broderick et al., 2008; Jenkins et al., 2014).

\section{Necessidade de Buscar seus Direitos}

Nos relatos de Ártemis e Hipólita, notou-se a necessidade vivida por elas de buscarem exercer seus direitos. Para tanto, recorreram a meios não convencionais ou a batalhas judiciais, já que não havia reconhecimento legal das respectivas relações. Dessa forma, um direito que uma viúva comum teria sem complicações, como por exemplo, os sete dias de licença do trabalho, teve de ser obtido por meio de uma licença de saúde, via atestado fornecido por uma médica que conhecia a história de Hipólita e sua esposa. Ártemis apenas conseguiu autorização para pas- 
sar duas horas com sua companheira na UTI ao alegar ser sua psicóloga. A herança que Ártemis teria direito desencadeou um processo judicial bastante burocrático e frustrante, pois a união estável teve de ser comprovada às pressas após a morte da cônjuge. Como demonstrado anteriormente, as batalhas judiciais e as dificuldades de acesso à esposa doente ou aos rituais fúnebres são intensificadoras de seu sofrimento. Contudo, essas foram experiências que também as impulsionaram como sujeitos de suas próprias vidas e afetos, em busca de exercer seus direitos e de terem suas vidas reconhecidas:

E ai eu resolvi fazer uma homenagem, né? Na formação, eu tava fazendo o curso de sexualidade, eu escrevi sobre o direito civil dos casais homoafetivos. Ai eu comecei a fazer pelo outro, né? Como uma forma de resiliência o que eu não soube fazer por mim, né? Então já me alegrou com a minha monografia, eu já soube de três pessoas que casaram, né? Duas fizeram a união estável e uma casou, né? No civil. Pensei "legal, a monografia já valeu!". (Ártemis)

\section{Necessidade de Autorrespeito}

e Autorreconhecimento como Lésbica

As entrevistadas relataram sobre a importância do reconhecimento e respeito a si mesmas como lésbicas. Segundo elas, o posicionamento e o respeito com sua sexualidade devem partir delas mesmas. Afirmam que se aceitar e se respeitar como homossexual implica não ser posteriormente acovardada e silenciada pela sociedade heteronormativa. Um silêncio que não protege ninguém, ao contrário, mascara e vela a vida dessas mulheres, impedindo-as de participarem livremente da vida social. As participantes afirmaram que o não se assumir ou o desrespeito a si, em nome do respeito ao outro, gera uma situação incômoda tanto enquanto o casal estiver junto (pois não há legitimação da relação, permitindo às vezes muitas interferências externas na vida do casal), quanto após a morte de uma das cônjuges (em que não há reconhecimento do estado de viuvez). Por isso, ambas ressaltaram a importância do posicionamento social do casal antes do falecimento, revelando um aspecto das possibilidades que se ampliaram com a experiência de luto e de suas possibilidades pessoais de transformação diante da dor. Nas palavras de Hipólita:

. . . em relação ao silêncio né, um silêncio né, um silêncio que não nos protege né? Nos protege de quê? Você sabe que eu comecei a ficar muito mais feliz na minha vida, de uns dez anos pra cá, quando eu assumi essa militância lésbica mesmo, depois da morte dela. Assumi mesmo, e eu fico muito mais, mais tranquila quando eu digo " $\mathrm{Ah}$, eu sou lésbica", sabe? Me tranquilizou muito o coração, sabe? De você poder dizer "Ah, que se dane o preconceito todo, que se dane", sabe? Porque é muito ruim essa coisa do meio termo, você fala e você não fala, $e$ como é que é?

O posicionamento social do casal, tal como descrito na literatura (Broderick et al., 2008), influenciará no grau de acolhimento que a viúva receberá, já que expor sua relação com outra mulher estaria relacionado a um aumento de apoio social na viuvez, embora possa ser ameaçador para sua segurança. Por outro lado, viúvas que não revelam a natureza de seus relacionamentos demonstraram mais fortemente sentimentos de solidão e isolamento (Jenkins et al., 2014), mostrando que, apesar dos riscos, este pode ser um fator protetivo para o sofrimento do luto na viuvez lésbica.

Broderick et al. (2008) afirmaram que a morte de um cônjuge pode trazer reavaliações no papel assumido pelo enlutado antes da morte, na sua identidade, valores e expectativas que contribuem no sentido e no propósito da vida. Após a morte de sua esposa, Hipólita assumiu sua militância lésbica. Porém, o engajamento existencial foi também fortemente evidenciado no caso de Ártemis, que relatou que após as frustrações vividas com a família de sua esposa durante o processo de adoecimento e após seu falecimento, aprendeu a respeitar a si mesma, pois sofreu consequências negativas por ter aberto mão de si em nome do respeito aos outros. Hoje ela se considera diferente em relação a esta questão: "Hoje eu vejo também na hora da gente 
em nome de respeitar o outro, a gente se desrespeita, a consequência é essa, é o que eu vivo, né?". Ambas afirmam terem aderido a diferentes tipos de militância após a morte de suas esposas, apontando para o luto como possibilidade de transformação de sua posição diante da própria vida social como lésbica.

\section{Conclusão}

No levantamento bibliográfico das produções no Brasil sobre o tema não foram encontrados artigos referentes à viuvez de lésbicas. Considerando que as produções acadêmicas refletem questões presentes e discutidas na sociedade, nota-se que no meio internacional o cenário quanto às causas LGBT está mais avançado, incluindo a compreensão do processo de enlutamento nessa população. A inexistência de artigos brasileiros sobre o luto entre casais homossexuais, especialmente lésbicos, aponta para a invisibilidade e um não reconhecimento dessas relações em nossa sociedade, mantendo a discussão restrita, como apontado pelos depoimentos, mesmo quando se considera os grupos ativistas. O estado da arte corrobora a preocupação - também apresentada nos resultados - em se ater ao enfrentamento social da questão, desconstruindo diferenças criadas e o preconceito sedimentado quanto às uniões homossexuais, hoje também marcadas pelo reconhecimento via afeto e não simplesmente reconhecidas como um direito civil (Costa \& Nardi, 2015).

Uma das limitações do presente estudo é que não se investigou profundamente questões de raça, idade e o período em que esses casais viveram, o que de certo apontaria para experiências diferentes, além de estudos que repensem os desafios no recrutamento dessa população, em uma tentativa de ampliar o número de participantes em estudos posteriores. A despeito de demonstrar que, mesmo com um lapso de 15 anos entre as duas experiências de viuvez, há uma semelhança com relação às dificuldades enfrentadas pelas entrevistadas em relação aos vínculos sociais e a aceitação delas como ser-casal.

O trabalho assinala claramente a necessidade de combater a invisibilidade da viuvez entre lésbicas, especialmente no que tange aos impactos em sua saúde e nas relações familiares. Um dos aspectos de maior relevo evidenciado foi a questão do quanto são impactantes no luto por viuvez, tanto o vínculo de afeto existente entre o casal, quanto o reconhecimento social do casal enquanto casal legítimo, questão essa de difícil manejo. As próprias experiências das entrevistadas são marcadas por uma busca de reconhecimento de suas relações e seus afetos, muitas vezes permeadas pela decepção, isolamento, solidão e por diversos outros conflitos da não aceitação de seus relacionamentos e sexualidade, seja socialmente, seja pela família. Contudo, esta é uma questão que permeia não apenas os processos de enlutamento, porém, se faz presente existencialmente para homossexuais ao longo de toda sua vida, sendo sempre um aspecto que se coloca em jogo na relação, com ganhos e riscos às vezes evidentes, outras vezes nem tanto, sendo necessária a avaliação do "revelar-se" tanto como fator protetivo, quanto como fator de risco.

Diante de tal complexidade, destaca-se que o problema de serem reconhecidas como casal, e consequentemente como lésbicas, possui implicações no enlutamento. Nota-se que o não enfrentamento social está claramente associado a um maior sofrimento das viúvas em seu luto, demonstrando o quanto essas questões estão intrincadas com as experiências subjetivas.

Tal constatação nos remete a duas pontuações relevantes, uma de ordem teórica, a outra de ordem prática. A primeira, teórica, diz respeito à impossibilidade de se pensar o enlutamento fora de seu horizonte histórico de possibilidades, onde a ausência de alguém significativo adquire um contorno histórico pela via do conflito existencial, pois foi exigido das enlutadas um posicionamento subjetivo diante da vida social - assumir-se lésbica ou não. Tal questão revela a necessidade de reconhecer a dimensão existencial como histórica e não como uma esfera dada no campo do ideal, assim como o enlutamento. A segunda pontuação diz respeito ao fato de que o profissional de saúde que pretende acolher estas mulheres deve estar atento ao problema de que a visibilidade da relação lésbica 
produz impactos no enfrentamento do luto e sua dor, tendo como tarefa entender estes impactos e investigá-los no contexto de vida de cada enlutada, pois apesar de seu aspecto social, cada luto ocorre sempre dentro do contexto de uma vida. Destaca-se ainda que entender tais impactos não significa em absoluto um "dever escolher" diante das possibilidades que se colocam, mas problematizá-los em todos seus matizes e contornos. Assim, na mesma direção, não é possível uma defesa de um revelar-se como sinônimo de não sofrimento, pois há várias questões em jogo para além das batalhas judiciais no luto. Não que essas não sejam angustiantes, frustrantes nem tampouco relevantes, mas são apenas aspectos do problema.

Nota-se que a legitimação da viuvez está relacionada ao reconhecimento do casal e ao posicionamento social deste antes do falecimento. É importante ressaltar que, conforme o relato de Hipólita, nem mesmo dentro do próprio movimento LGBT o sofrimento dela fora reconhecido. A participante afirmou que a viuvez lésbica ainda não está incorporada na vida das pessoas, essas supondo sempre que as viúvas sejam heterossexuais.

Conclui-se que rede de apoio e espaços de acolhimento estruturados são fundamentais para que a experiência de perda possa ser legitimada e ganhe possibilidade expressiva para a ressignificação da experiência de luto e a minimização de seu sofrimento e consequências. Como apontado na literatura, a perda da cônjuge para a viúva lésbica pode remeter a outras perdas anteriores associadas à lesbofobia. Assim sendo, o profissional que atender uma enlutada lésbica deve interessar-se por conhecer a relação entre as famílias, que apresentam muitos matizes entre a aceitação e a recusa do relacionamento, buscando também delinear a rede de suporte disponível, além de disponibilizar-se à abertura de novos espaços para ressignificação.

\section{Referências}

Bent, K. N., \& Magilvy, J. K. (2006). When a partner dies: Lesbian widows. Issues in Mental Health Nursing, 27, 447-459. doi:10.1080/01612840600599960
Bristowe, K., Marshall, S., \& Harding, R. (2016). The bereavement experiences of lesbian, gay, bisexual and/or trans people who have lost a partner: A systematic review, thematic synthesis and modelling of the literature. Palliative Medicine, 30(8), 730-744. doi:10.1177/0269216316634601

Broderick, D. J., Birbilis, J. M., \& Steger, M. F. (2008). Lesbians grieving the death of a partner: Recommendations for practice. Journal of Lesbian Studies, 12, 225-235. doi:10.1080/10894160802161380

Costa, A. B., \& Nardi, H. C. (2015). O casamento "homoafetivo" e a política da sexualidade: Implicações do afeto como justificativa das uniões de pessoas do mesmo sexo. Revista Estudos Feministas, 23, 137-150. doi:10.1590/0104$-026 X 2015 \mathrm{v} 23 \mathrm{n} 1 \mathrm{p} / 137$

Ferreira, L. C., Leão, N. C., \& Andrade, C. C. (2008). Viuvez e luto sob a luz da Gestalt-terapia: Experiências de perdas e ganhos. Revista da Abordagem Gestáltica, 14, 153-160. Recuperado em http://pepsic.bvsalud.org/scielo.php?script $=$ sci_ arttext\&pid=S1809-68672008000200002

Freitas, J. L. (2013). Luto e fenomenologia: Uma proposta compreensiva. Revista da Abordagem Gestáltica, 19, 97-105. Recuperado em http://pepsic.bvsalud.org/scielo.php?script=sci_ arttext\&pid=S1809-68672013000100013\&lng= pt\&tlng=pt.

Freitas, J. L., Michel, L. H. F., \& Zomkowski, T. L. (2015). Eu sem tu: Uma leitura existencial do luto em psicologia. In J. L. Freitas \& M. V. F. Cremasco (Eds.), Mães em Luto (pp. 16-21). Curitiba, PR: Juruá.

Giorgi, A., \& Sousa, D. (2010). Método fenomenológico de investigação em psicologia. Lisboa: Fim de século.

Hart, C. F. M. (2008). Perdas e Processos de Luto. In M. Paraiba \& M. R. da Silva (Eds.), Câncer: Uma abordagem psicológica (pp. 153-166). Porto Alegre, RS: AGE.

Instituto Brasileiro de Geografia e Estatística. (2014). Estatísticas do registro civil. Recuperado em https://ww2.ibge.gov.br/home/estatistica/populacao/registrocivil/2014/default.shtm

Jenkins, C. L., Edmundson, A., Averett, P., \& Yoon, I. (2014). Older lesbians and bereavement: Experiencing the loss of a partner. Journal of Gerontological Social Work, 57, 273-287. doi: 10.1080/01634372.2013.850583 
Kovács, M. J. (1992). Morte, separação, perdas e o processo de luto. In M. J. Kovács (Ed.), Morte e desenvolvimento humano (3. ed., pp. 149-164). São Paulo, SP: Casa do Psicólogo.

Lenhardt, A. M. C. (1997). Grieving disenfranchised losses: Background and strategies for counselors. Journal of Humanistic Education and Development, 35, 208-216. doi:10.1002/j.2164-4683.1997.tb00371.x

Parkes, C. M. (1998). Luto: Estudos sobre a perda na vida adulta. São Paulo, SP: Summus.

Stevens, P. E., \& Hall, J. M. (1998). Stigma, health beliefs and experiences with health care in lesbian women. IMAGE: Journal of Nursing Scholarship, 20(2), 69-73. doi:10.1111/j.1547-5069.1988.tb00033.x

Supremo Tribunal Federal. (2011, 05 maio). Supremo reconhece união homoafetiva [Notícia]. Recuperado em http://www.stf.jus.br/portal/cms/verNoticiaDetalhe.asp?idConteudo $=178931$

Supremo Tribunal Federal. (2013, 20 maio). Resolução sobre casamento civil entre pessoas do mesmo sexo é aprovada pelo Conselho Nacional de Justiça [Notícia]. Recuperado em http:// www2.stf.jus.br/portalStfInternacional/cms/destaquesNewsletter.php?sigla=newsletterPortalIn ternacionalDestaques\&idConteudo $=238515$
Turatti, B. O. (2012). Implicações da viuvez na saúde: Uma abordagem fenomenológica em Merleau-Ponty. Saúde \& Transformação Social, 3, 32-38. Recuperado em http://pepsic.bvsalud. org/scielo.php?script=sci_arttext\&pid=S2178$-70852012000100006 \& \operatorname{lng}=$ pt\&tlng=pt.

Whipple, V. (2006). Lesbian widows: Invisible grief. New York: Harrington Park Press.

Whipple, V. (2007). Working with lesbian widows. Grief Matters: The Australian Journal of Grief and Bereavement, 10(1), 4-7. Retrieved from http://search.informit.com.au/documentSummar y;dn=056427304773984;res=IELHEA

Whitman, J. S., Cormier, S., \& Boyd, C. (2000). Lesbian identity management at various stages of the coming out process: A qualitative study. International Journal of Sexuality and Gender Studies, 5, 1-104.doi:10.1023/A:1010181416984

Recebido: 09/06/2016

$1^{a}$ revisão: 25/07/2016 Aceite final: 26/07/2016 